\title{
Viabilidade de Extratos Etanolicos de Folhas de Lobeira (SOLANUN LYCOCARPUM ST. HILL) no Controle de Fungos de Interesse Médico
}

\section{Viability of Lobeira Leaf Ethanol Extracts (SOLANUN LYCOCARPUM ST. HILL) in the Control of Fungi of Medical Interest}

Luís Fernando Albarello Gellen ${ }^{1}$, Aline Torquato Tavares², Francielly Quitéria Guimarães Alves $^{3}$, Marllos Peres de Melo4, Valéria Gomes Momenté ${ }^{4}$, Ildon Rodrigues do Nascimento ${ }^{5}$

\section{RESUMO}

Plantas com atividades medicinais têm sido utilizadas pelo homem ao longo de sua história, muitas delas são utilizadas para o tratamento de doenças infecciosas, inclusive causadas por fungos. Este trabalho avaliou o potencial antifúngico de extratos de folhas de lobeira em fungos da espécie C.albicans, C. parapisilosise C. luzitania.Os testes para determinar a atividade antifúngica foram o teste de concentração inibitória mínima e máxima (CIMM), curva cinética de crescimento fungíco e teste de disco-difusão. Os testes comprovaram a atividade antifúngica de extratos de folhas de lobeira a partir da concentração de $60 \mathrm{mg}$. Outro teste realizado foi o de citoxicidade a células humanas utilizando células mielocíticas THP-1, onde o extrato de lobeira apresentou atividade citotóxica a cima de $100 \mathrm{mg}$ de concentração de extrato de lobeira. Portanto os extratos de lobeira tematividade antifúngica e podem ser utilizados para o tratamento de fungos das espécies C.albicans, C. parapisilosise C. luzitania.

Palavras-Chave: C.albicans. C. parapisilosis. C. luzitania.

\section{ABSTRACT}

Plants with medicinal activities have been used by man throughout his history, many of them are used for the treatment of infectious diseases, including fungal. This study evaluated the antifungal potential of wolf gray leaf extracts in fungi of species $\mathrm{C}$. albicans, C. parapisilosis and C. luzitania. The tests to determine the antifungal activity were the maximum and minimum inhibitory concentration test (CIMM), kinetic curve of fungal growth and disk diffusion test. The tests proved the antifungal activity of wolf gray leaf extracts from the concentration of $60 \mathrm{mg}$. Another test was performed cytotoxicity to human THP-1 cells using myelocytic cells, where the lycocarpum extract showed cytotoxic activity up to $100 \mathrm{mg}$ lycocarpum extract concentration. Therefore, the extracts lobeira antifungal tivity subject and may be used for the treatment of fungal species $\mathrm{C}$. albicans, C. parapisilosis and C. Luzitania.

Keywords: C.albicans. C. parapisilosis. C. luzitania. 


\section{INTRODUÇAO}

O Brasil é um dos países que apresenta maior biodiversidade do mundo, estima-se que entre 10 e $12 \%$ de todas as espécies descritas mundialmente, são encontradas no país e aproximadamente $19 \%$ da flora mundial estão distribuídas nos seis biomas do Brasil, sendo eles o Cerrado, os Campos Sulinos, a Floresta Atlântica, a Caatinga, a Floresta Amazônica e o Pantanal (RIBEIRO \& WALTER, 2008; PASSOS, 2009).

Apesar da enorme biodiversidade, no Brasil poucos grupos de pesquisa investigam a validação do uso de plantas nativas e as práticas populares relacionadas com seu uso, por isso, as informações científicas ainda são insuficientes para a maioria das plantas medicinais, de modo a garantir a qualidade, segurança e eficácia.

Compostos fungicidas originados de plantas do cerrado ocupam um papel de destaque nas linhas de pesquisa, uma vez observado que várias destas plantas têm sua própria defesa contra fungos fitopatógenos, esta defesa é decorrente da produção de metabólitos secundários (SIMÕES et al., 2010).

Solanum lycocarpum St. Hill. (do grego "lycos" = lobo e "karpos" = fruto), da família das Solanaceae é um arbusto comum no bioma do Cerrado, na parte central do Brasil, com frutos globosos e verdes (SCHWARTZ et al., 2007; PINTO et al., 2007; NAKAMURA et al., 2008, VAZ, 2010). Popularmente conhecida como "lobeira" nas regiões norte e nordeste do país (MIRANDA, 2010).

A lobeira produz metabólitos secundários como a solamina, solamargina, taninos e flavonóides. A solamina e solamargina podem ser utilizadas como matéria prima de precursores hormonais, os taninos e flavonóides no combate ao envelhecimento precoce e câncer de pele (MAURYA et al., 2009).

Além destas propriedades medicinais relatadas por produzirem estes metabólitos secundários a lobeira apresenta outras substâncias com potencial medicinal, como é o caso do amido presente nos frutos, apresenta potenciais hipoglicemiantes, combatendo diabetes tipo II, obesidade e problemas ligados a elevados níveis de colesterol. Outros bioativos apresentam atividade diurética, antiespasmolítica, sedativa, antiofídica, antiparasitária e atividades anti-inflamatórias (ALONSO-CASTRO et al., 2012; HERNÁNDEZ-ORTEGA et al., 2012; AL-ASHAAL, 2010; MORENO-SALAZAR et al., 2008; FARINA et al., 2010).

Pela presença de vários bioativos na lobeira, suas várias aplicações na terapia clínica e farmacológica o objetivo do trabalho foi avaliar o potencial inibitório e atividade fungicida do extrato alcoólico de folhas de lobeira (Solanum lycocarpum St. Hill.) em cepas de 
Cândida albicans, Cândida parapsilosis e Cândida luzitânia. Avaliar a citoxicidade de concentrações de extrato foliar de lobeira em linhagens mielocíticas THP-1.

\section{MATERIAIS E METODOS}

A seguir, serão apresentados o local, como o material vegetal foi coletado e como foi preparado o extrato etanólico, e como foi realizado o teste de atividade antifúngica.

\subsection{Local}

Os experimentos foram realizados nos Laboratórios de Microbiologia e Vacinologia da Universidade Federal do Tocantins (UFT), Campus Universitário de Gurupi.

\subsection{Coleta do Material Vegetal e Preparação do Extrato Etanólico}

As folhas de $S$. lycocarpum St. Hill foram coletadas nos municípios de Cristalândia TO, coordenadas: (10³4'49.82"S/495'37.43"O);(10³4'51.75"S / 49॰5'33.56"O); (10³4'49.98"S/495'28.86"O); (10³4'49.74"S/495'30.07"O);

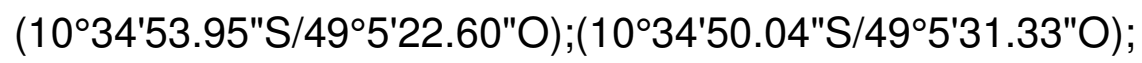
(10³4'48.16"S/49 $\left.{ }^{\circ} 5^{\prime} 21.53 " \mathrm{O}\right) ;\left(10^{\circ} 34^{\prime} 48.61 " \mathrm{~S} / 49^{\circ} 5^{\prime} 18.66 " \mathrm{O}\right)$;

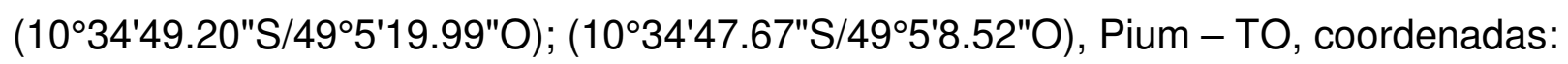
(10²7'54.63"S/49¹0'59.52"O); (10²7'53.88"S/49¹1'11.21"O); $\left(10^{\circ} 27^{\prime} 49.28^{\prime \prime S} / 49^{\circ} 11^{\prime} 0.95 " O\right)$, Correntina - BA e Barreiras - BA, coordenadas:

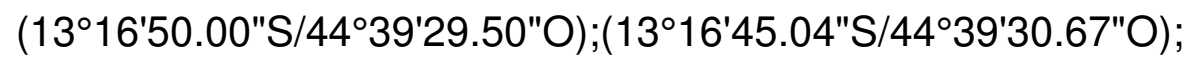

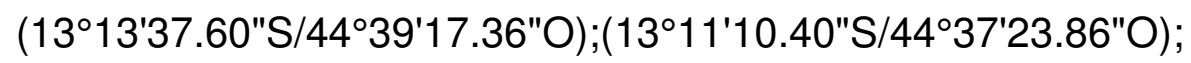

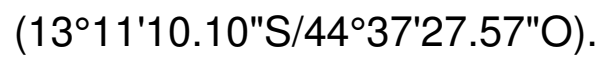

Em cada local foram coletadas folhas da região mediana das plantas. Após as coletas as folhas foram armazenadas em sacos plásticos com identificação. Em laboratório, as folhas foram submetidas ao processo de lavagem com hipoclorito a $3 \%$ e água corrente, em seguida submetidas a secagem em estufa de secagem com entrada de ar forçada a $37^{\circ} \mathrm{C}$ até atingirem peso constante.

Com o material foliar desidratado, as folhas foram trituradas em liquidificador industrial com o intuído de aumentar a penetração do solvente ao soluto. Em seguida para formar a solução de extração, foi utilizada a proporção de 40/60, onde 400 gramas de pulverizados foram adicionados a $600 \mathrm{ml}$ de etanol absoluto. 
Posteriormente a solução foi submetida a ambiente ausente de luz pelo período de 24 horas a $25^{\circ} \mathrm{C}$, sob agitação continua em shaker orbital a $250 \mathrm{rpm}$. Concluída esta etapa de descanso da solução, foi submetida a procedimentos de filtração, iniciando por filtração a vácuo seguida de filtração em filtro milliporo (Milliporo K18-230) com vasão do poro de 0,22 $\mu \mathrm{m}$.

Após os processos de Filtração o etanol presente na solução foi extraído por processo de evaporação em evaporador rotativo (Quimis $-Q 344 \mathrm{~B}$ ) a $60^{\circ} \mathrm{C}$ e o resíduo resultante foi re-extraído utilizando o fluxo de ar da capela de fluxo laminar durante $24 \mathrm{~h}$., resultando em apenas o concentrado foliar bruto de $S$. lycocarpum.

\subsection{Testes de Atividade Antifúngica}

Para os testes de atividade antifúngica, foram utilizados os seguintes fungos $C$. albicans, C. parapsilosise C. luzitânia, microrganismos estes cedidos pelo LACEN-TO (Laboratório Central do Tocantins).

\subsubsection{Concentração Inibitória Mínima e Máxima - CIMM}

Foi determinado através da metodologia de micro poços em meio sólido Muller Hilton (NCCLS, 2008). Para isso, as colônias de cada cepa foram fortalecidas previamente por um período de 48 horas a $37^{\circ} \mathrm{C}$ em meio $\mathrm{BHI}$. Após esse processo uma alíquota foi suspendida e ajustada para a turvação de 0,5 da Escala de McFarland (LENETTE et al.,1987).

Em meio Muller Hilton foram semeadas as cepas pelo método de esgotamento de alça, foram realizadas perfurações no meio de cultura com cerca de $6 \mathrm{~mm}$ de diâmetro, nos orifícios foram adicionadas concentrações do extrato, que foram de 0 a $200 \mathrm{mg}$, com diferença entre as doses de $10 \mathrm{mg}$, posteriormente incubadas por um período de 24 horas a $37^{\circ} \mathrm{C}$. Para determinar a concentração inibitória mínima e máxima foi utilizada a metodologia de Silva et. al.(2009), sendo adaptada com o seguinte parâmetro, a concentração inibitória mínima será considerada a partir da menor concentração testada, isto quando ela apresentar halo superior a $10 \mathrm{~mm}$, a máxima quando a maior concentração de extrato apresentar uma progressão menor que $3 \mathrm{~mm}$ em comparação a concentração anterior. 
Este teste é uma adaptação da curva cinética bacteriana e se baseia na metodologia de Peyret et al. (1990).

Determinadas as curvas cinéticas de todos os microrganismos, seus pontos e tempo de estabilidade nas fases lag, exponencial, estacionária e declínio. Utilizando os valores de atividade inibitória mínima e máxima das concentrações do teste CIMM, realizou-se novamente o teste da curva cinética de crescimento, contudo utilizando as concentrações de extrato de S. lycocarpum St. Hill., estas adicionadas ao meio BHI liquido contendo as bactérias.

Nesta metodologia haverá um padrão para as concentrações dos extratos, isto para anular a absorbância gerada pelo extrato e permitir observar apenas a multiplicação bacteriana.

\subsubsection{Teste de Disco-Difusão em Ágar}

Os testes de disco-difusão foram realizados segundo o Comitê Nacional de Normas de Laboratório Clinico (NCCLS, 2008). Com auxílio de uma alça bacteriológica foram retiradas alíquotas bacterianas fortificadas, estas adicionadas em soro fisiológico estéril e ajustadas para turvação de 0,5 na escala de McFarland (LENETTE et al.,1987).

Os discos foram confeccionados de acordo com as concentrações do teste de CIMM, utilizando como controle negativo um disco com apenas agua, os controles positivos foram determinados de acordo com cada descrição contida no NCCLS para cada estirpe bacteriana, portanto para Pseudômonas aeroginosaATCC 27853 foi utilizada a gentamicina $10 \mathrm{mg}$; Escherichia coli ATCC 35218 a ampicilina com sulbactam 20 mg; StreptococcuspyogenesATCC 19615 utilizou a penicilina G $10 \mathrm{mg}$ e Sthaphylococcus aureus ATCC 25923 a amoxicilina com ácido clavulânico 30 mg. Caso ocorrer resistência bacteriana o controle positivo e alterado segundo as especificações do NCCLS (2008).

Todos os discos foram pressionados suavemente contra o meio de cultura, as distâncias entre os discos foram de $30 \mathrm{~mm}$ e da margem da placa de $15 \mathrm{~mm}$, para assim impedir a superposição de halos de inibição.

As placas foram incubadas em estufa a $37^{\circ} \mathrm{C}$ por 24 horas, após este período realizada a leitura com auxílio de um paquímetro. Cada concentração foi avaliada em 10 
repetições para todas as cepas bacterianas, para assim obter-se uma média do valor de inibição percentual.

\subsubsection{Teste de Viabilidade Celular com Linhagem Mielomonocíticas Humana THP-1}

O teste de viabilidade celular utilizando linhagem ATCC THP-1 seguiu a metodologia descrita por Mosmann (1983).

Para manutenção da linhagem celular THP-1 foi realizada utilizando meio de cultura RPMI, suplementado com soro feral bovino (10\%), antibióticos $(10,000 \mathrm{U} / \mathrm{mL}$ de penicilina e $10 \mathrm{mg} / \mathrm{L}$ de estreptomicina) e bicarbonato $(0,6 \mathrm{~g})$. As células foram incubadas em atmosfera úmida de $5 \%$ de $\mathrm{CO}_{2}$, a $37^{\circ} \mathrm{C}$.

As células THP-1 foram contadas em câmara de Neubauer, para assim determinar a quantidade especifica de células pipetadas em cada poço, para o teste determinou-se a quantidade de $1 \times 10^{4}$ células para cada poço. A quantidade de reagentes para cada poço foi a seguinte: $50 \mathrm{ml}$ da solução celular de THP-1 para $1 \mathrm{ml}$ de meio, adicionando as concentrações do extrato a serem testadas. Incubar em estufa de $\mathrm{CO}_{2}$ na concentração de $5 \%$ a $37^{\circ} \mathrm{C}$ por um período de 48 horas, após este período pipeta-se o reagente MTT (100 microlitros), aguardando 4 horas para realizar a leitura em espectrofotômetro no comprimento de onda de $540 \mathrm{~nm}$.

Para o teste de viabilidade além do controle normal do teste (células THP-1 mais Meio), foi necessário um controle de subtração, isto pelo fato do extrato apresentar coloração intensa, neste caso o controle será o extrato mais meio, para que seja eliminada a absorbância do extrato.

A fórmula para encontrar absorbância real dos testes (observar fórmula abaixo), onde a absorbância do teste e subtraída pela absorbância do extrato controle, deste modo obtemos a absorbância real do teste.

$$
\text { Abs. Real do Teste }=\frac{\text { Abs. Teste }}{\text { Abs. Extrato Controle }}
$$

Obtidas as absorbâncias reais, estas são comparadas a absorbância padrão do teste, onde se as absorbâncias dos testes forem maiores que a do padrão o extrato não e viável para células humanas, assim citotóxico. 


\section{RESULTADOS E DISCUSSAOO}

A seguir, serão apresentados os resultados e discussão obtidos nesse trabalho.

\subsection{Concentração Inibitória Mínima e Máxima - CIMM}

Constatou-se que a concentração inibitória mínima para as espécies de C. albicans, C. lusitâniae C. parapisilosis é de $60 \mathrm{mg}$, sendo sua concentração inibitória máxima de 100 $\mathrm{mg}$, conforme apresentado na Tabela 1.

Tabela 1. Resultados do teste de concentração inibitória mínima e máxima. Gurupi, Tocantins, Brasil, 2014.

\begin{tabular}{c|c|c|c}
\hline Fungos & Concentração de Extrato $(\mathbf{m g})$ & $\operatorname{CIMin}(\mathbf{m m})$ & $\operatorname{CIMax}(\mathbf{m m})$ \\
\hline C.albicans & $60-100$ & 12,7 & 14,3 \\
\hline C. luzitania & $60-100$ & 19,5 & 34,6 \\
\hline C. parapsilosis & $60-100$ & 9,55 & 29,65 \\
\hline
\end{tabular}

As médias de inibição das CIMin e CIMax com maior halo de sensibilidade ocorreram no teste com a espécie C. luzitania, a média de seus halos da CIMin foi de 19,5 mm e sua CIMax de 34,6 mm. Seguido pelos valores de inibição da C. albicans $12,7 \mathrm{~mm}$ e 14,3 mm e pelas médias de inibição do teste com C. parapisilosis9,55 e 29,65 mm.

Este potencial antifúngico de extratos de lobeira foi demonstrado por Costa e Bara (2004), os resultados foram positivos no teste de concentração inibitória mínima contra fitopatógenos, eles ainda sugerem a que mesma atividade possa ser reproduzida em fungos dermatófitos.

A afirmação de Costa e Bara (2004) é comprovada com este experimento de atividade antifúngica, assim o potencial antifúngico de extratos de folhas de lobeira tem ação em dermatófitos da espécie Candida albicans, C. parapisilosise C. luzitania. Punjabi et al.(2008) atribui o potencial antifúngico da lobeira e atribuem aos alcalóides e saponinas presentes na estrutura do vegetal.

Os resultados obtidos estabeleceram as concentrações em que serão testadas em outros testes como cinética antifúngica com extratos e teste de disco-difusão. 


\subsection{Cinética de Crescimento Fúngica}

As espécies de Cândida albicans, C. parpisilosise $C$. luzitânia entram em fase de declínio após 700 minutos após incubação (Figura 1).

Esta demora no crescimento fúngico destas espécies ocorre porque estas cepas são consideradas dimórficas, esta característica confere a estas espécies a forma micelial em temperatura ambiente e leveduriforme a $37^{\circ} \mathrm{C}$. Portanto o evento do dimorfismo e 0 arcabolso genético mais complexo que bactérias faz com que a curva cinética de crescimento decorra por mais tempo.

Figura 1. Curva cinética fúngica de cepas de Candidaalbicans, $C$. parapisilosis e $C$. luzitaniaem função da determinação das fases lag, exponencial, estacionária e de declínio de cada fungo, Gurupi, Tocantins, Brasil, 2014.

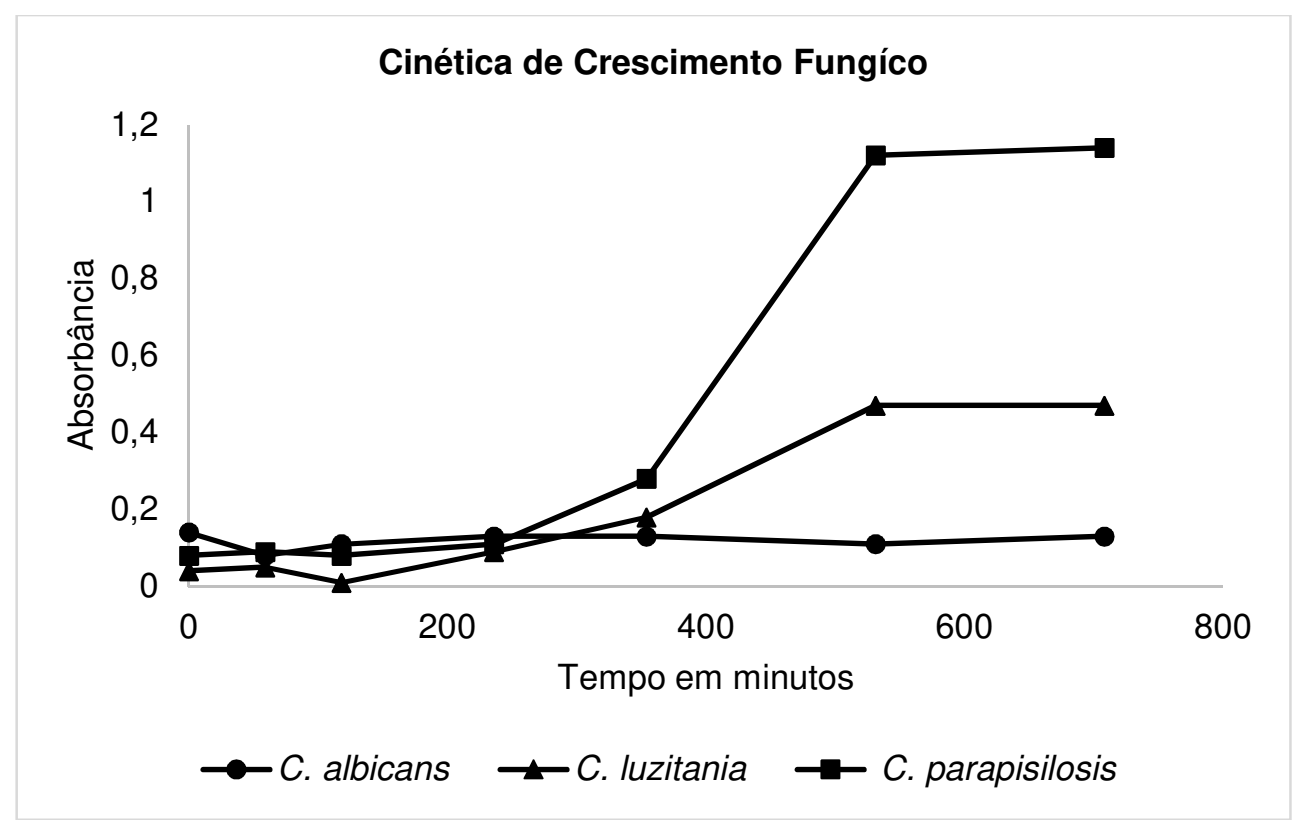

Traçadas as fases da curva de todos os fungos em teste, realizou-se uma nova curva cinética de crescimento fúngico, acrescentando ao meio as concentrações de extrato utilizadas no teste de CIMM.

A curva cinética da C. albicans, C. parpisilosise C. luzitâniacom adição de extratos de lobeira estão dispostos na Figura 2.

Pode-se observar na Figura 2 uma redução no tempo da curva cinética de ambas as espécies de Candidassp., a entrada na fase de declínio na cinética fúngica inicia-se aos 700 minutos de teste, com a adição de extratos de lobeira a queda para 300 minutos com 
as cepas de $C$. albicans, a cepa de $C$. lusitania entra na fase de declínio aos 300 minutos e a cepa de $C$. parapisilosis aos exatos 240 minutos de teste.

A cepa de C. parapisilosis, após a entrada na fase de declínio aos 360 minutos de teste os valores de concentração fúngica chegam aos valores do inóculo inicial $(0,20 \mathrm{~nm})$.

Ainda é observado na Figura 2 um fenômeno de resistência na concentração de 60 mg no teste com C. albicans, este evento ocorre justamente aos 60 minutos do teste, contudo sua fase de declínio ocorre com linearidade nas demais concentrações testadas (80 e $100 \mathrm{mg})$.

Figura 2. Curva cinética de $C$. albicans, $C$. parpisilosise $C$. luzitaniautilizando diferentes concentrações de extrato de lobeira. Gurupi, Tocantins, Brasil, 2014.
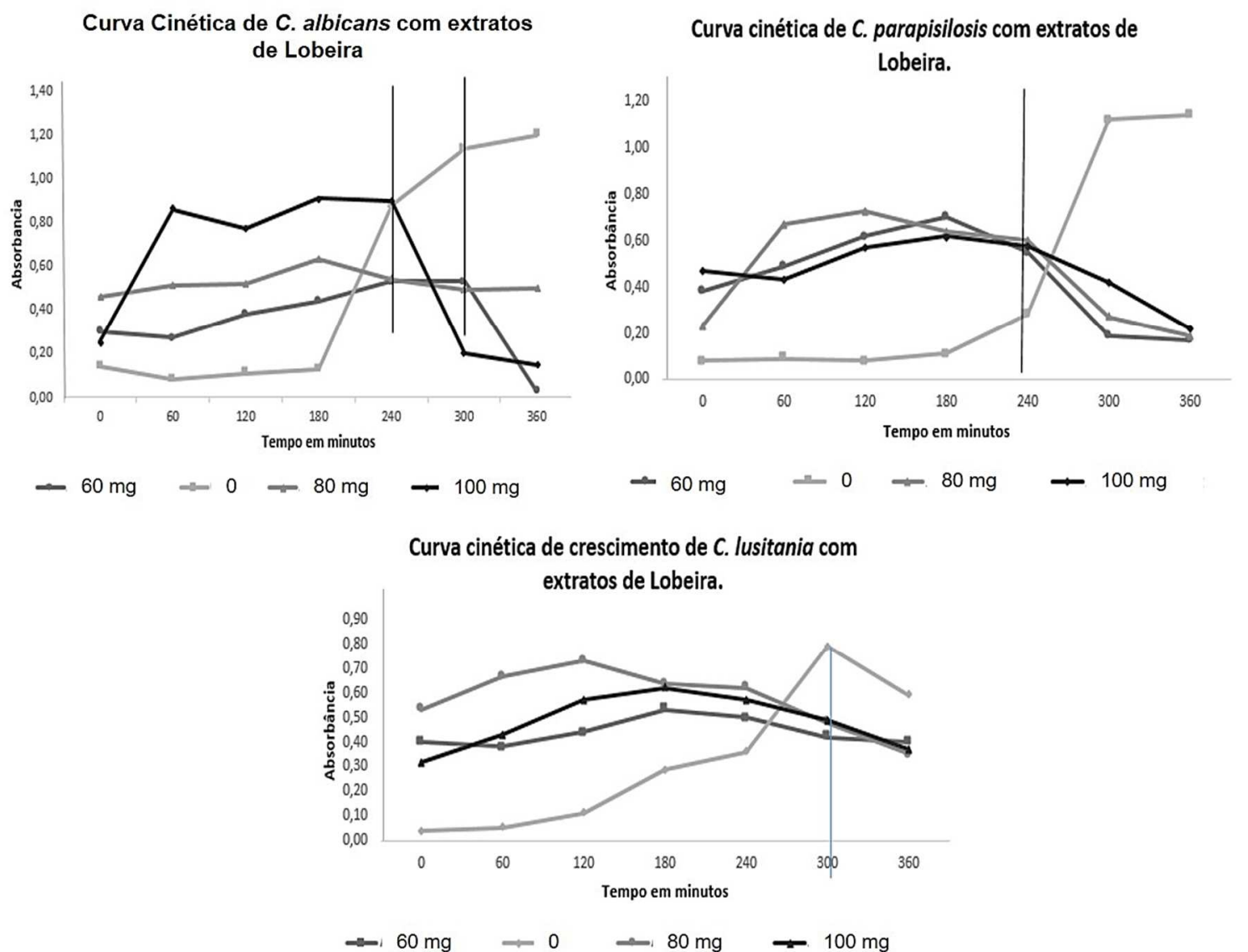

Com a cepa de C. Lusitânia ocorreram oscilações significativas em todas as concentrações de extrato foliar de lobeira, este fenômeno demonstrado na Figura 2, entretanto ainda ocorreu atividade antifúngica, isto observado pela entrada na fase declínio ocorrendo aos 300 minutos, quando no teste sem extratos esta fase se iniciou em 700 minutos de teste. 
Com estas curvas cinéticas traçadas pode-se confirmar a afirmação de Costa e Bara (2004), além de atividade antifúngica contra fitopatógenos o extrato de lobeira tem atividade contra dermatófitos, em especifico para espécies de $C$. albicans, $C$. lusitaniae $C$. parapisilosis.

\subsection{Teste de Disco-Difusão em Ágar}

As médias do teste de disco-difusão estão dispostos na Figura 3.

Verifica-se que há sensibilidade destes fungos ao extrato de folhas de lobeira. Entretanto a elevação da concentração não é proporcional a potência da atividade antifúngica, isto observado no extrato a $80 \mathrm{mg}$, nas espécies de $C$. albicanse $C$. parapisilosis.

Figura 3. Gráfico contendo as médias dos resultados do teste de disco-difusão com as cepas de $C$. albicans, $C$. parapisilosise $C$. luzitania, extratos estes nas concentrações de 60,80 e 100 mg. Gurupi, Tocantins, Brasil, 2014.

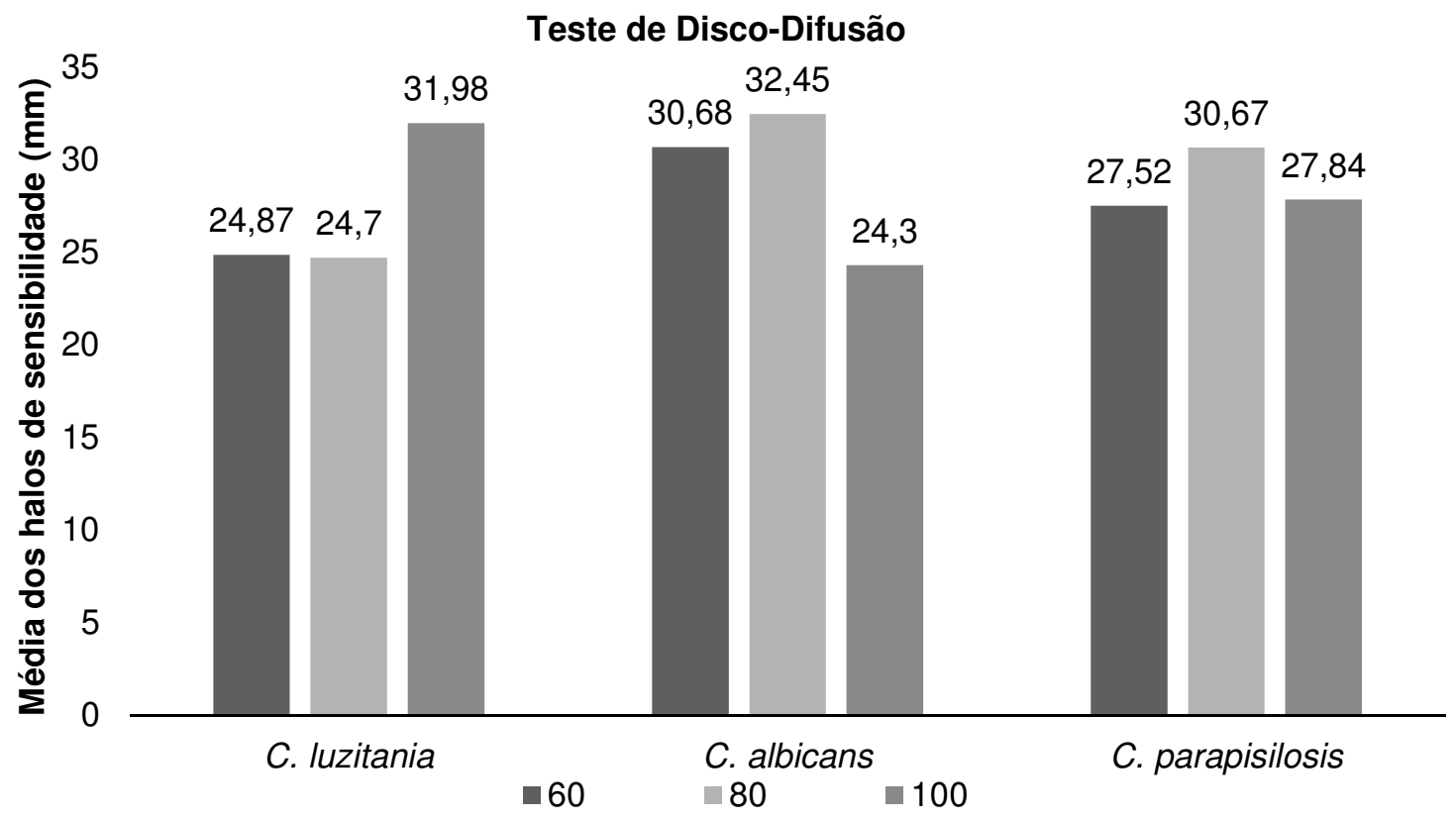

Resultando na eficiência da concentração de $80 \mathrm{mg}$ contra cepas de $C$. albicans $C$. parapisilosis respectivamente suas médias de halo foram de 32,45 e 30,67 mm. Entretanto na cepa de $C$. luzitaniaas médias das concentrações de 60 e $80 \mathrm{mg}$ foram equidistantes, na concentração de $100 \mathrm{mg}$ a média foi de $31,98 \mathrm{~mm}$.

Pujambi et al. (2008) testou atividade antifúngica dos frutos de lobeira, após comprovada sua atividade antifúngica, o pesquisado atribuiu esta ação aos metabólitos 
secundários, em especifico as saponinas contidas na polpa do fruto. Ainda Martins (2013) em seus testes com fruto da lobeira determinou que os extratos do fruto contem atividade antifúngica contra dermatofitoses.

Portanto os extratos foliares de lobeira contem atividade antifúngica perante as cepas de C. albicans, C. parapisilosise C. luzitania.

\subsection{Teste de Viabilidade Celular com Linhagem Mielomonocíticas Humanas THP-1}

Os resultados do teste de citoxicidade estão dispostos na Tabela 2. O valor de correção do extrato foliar de lobeira foi de 0,81 mn., medidas as absorbâncias do teste de citoxicidade utilizando células mielomonocíticas THP-1 ATCC, determinou que o extrato etanoólico bruto das folhas de lobeira apresentam citotoxicidade a partir de $100 \mathrm{mg}$ de extrato.

Tabela 2. Tabela com valores do teste de viabilidade celular, contendo valores e formula do fator de correção do extrato.

\begin{tabular}{c|c|c|c}
\hline Concentração (mg) & Absorbância Corrigida & Padrão & Abs. Extrato Controle \\
\hline 60 & 0,09 & 0,30 & 0,81 \\
\hline 80 & 0,19 & & \\
\hline 100 & 0,34 & & \\
\hline
\end{tabular}

Deste modo o extrato foliar de $S$. lycocarpum é viável, pois as concentrações em que o extrato apresentou maior atividade antifúngica foram na faixa de 60 - $100 \mathrm{mg}$, portando nesta faixa o extrato foliar de lobeira pode ser administrado a células humanas como fonte de tratamento.

\section{CONCLUSOES}

Extratos de lobeira apresentam potencial inibitório e atividade antifungica em cepas Cândida albicans, Candidaparapsilosis e Candidaluzitania.

Os extratos de folhas de lobeira apresentam citoxicidade a células humandas em concentrações acima de $100 \mathrm{mg}$, sendo assim viáveis para o tratamento de infecções fúngicas causadas por Candidaalbicans, Candidaparapsilosis e Candidaluzitania, pois a faixa de sensibilidade antifúngica foi de 60 - $80 \mathrm{mg}$ de extrato de lobeira. 


\section{REFERENCIAS}

AL-ASHAAL, HananAbdAl-Hay.Regeneration, in vitroglycoalkaloids production and evaluation of bioactivity of callus methanolic extract of Solanum tuberosumL. Fitoterapia.v. 81, n. 6 , p. 600-606, 2010.

ALONSO-CASTRO, AngelJosabad.Medicinal plants used in the HuastecaPotosina, México. Journal of Ethnopharmacology.v. 143, n. 1, p. 292-298. 2012.

COSTA, Ane Rosalina Trento; BARA, Maria Teresa Freitas.Atividade antifúngica de extratos de plantas sobre crescimento de fitopatógenos. Trabalho apresentado como pibic, Faculdade de Farmácia, UFG-GO, 2004. Disponível em: $<$ https://projetos.extras.ufg.br/conpeex/2004/pibic/Biol\%C3\%B3gicas/ane.html>. Acessoem: 13 ago. 2016.

FARINA, Fabiane et al. Glycemic and urinary volume responses in diabetic mellitus rats treated with Solanum lycocarpum.Applied Physiology, Nutrition and Metabolism, v. 35, n. 1, p. $40-44,2010$.

HERNÁNDEZ-ORTEGA Marcela et al.Antioxidant, Antinociceptive, and Anti-Inflammatory Effects of Carotenoids Extracted from Dried Pepper (Capsicum annuum L.). Journal of Biomedicine and Biotechnology. v. 2012, p. 10. 2012.

LENETTE, Edwin H; BALOWS, Albert; HAUSLER, William J.; SHADOMY, H.Jean. Manual de microbiologia clínica. 4. ed. Buenos Aires: Editorial Medica Panamericana, p. 1408, 1987.

MARTINS, GilmarcioZimmermman. Estudo Farmacognóstico e Screening Biológico de Solanumlycocarpum St. Hill (Solanaceae). 2013. 172 f. Tese (doutorado) - Universidade Estadual Paulista Júlio de Mesquita Filho, Faculdade de Ciências Farmacêuticas, 2013. Disponívelem: <http://hdl.handle.net/11449/104767>.

MAURYA, Anupam; GUPTA, Shalini; NEGI, Suroochi; SRIVASTAVA, Santosh Kumar. pHZone-refining centrifugal partition chromatography for preparative isolation and purification of steroidal glycoalkaloids from Solanum xanthocarpum. JournalofSeparation Science, v. 32, n. 18, p. 3126-3132, 2009.

MIRANDA Mariza Abreu. Avaliação do potencial antiparasitário do extrato alcaloídico e de alcalóidesesteroidais dos frutos de Solanumlycocarpum A. St.-Hil. Pharm. D. Thesis. Faculdade de Ciências Farmacêuticas de Ribeirão Preto, Universidade de São Paulo, Ribeirão Preto, Brasil; p. $\quad$ 97, $2010 . \quad$ Disponível em: <http://www.teses.usp.br/teses/disponiveis/60/60138/tde-04112010-161118/ptbr.php>. Acesso em 01 de jun. 2017.

MORENO-SALAZAR, Sergio Francisco; ROBLES-ZEPEDA, Ramon Enrique; JOHNSON, Donald E. Plant folk medicines for gastrointestinal disorder samong the main tribes of Sonora, Mexico. Fitoterapia, v. 79, p. 132-141. 2008. 
MOSMANN Tim. Rapid colorimetric assay for cellular growth and survival: application to proliferation and cytotoxicity assays. Journal of Immunological Methods.v. 65, n. 1-2, p. 5563. 1983.

NAKAMURA, Seikou et al. Steroidal Saponins and Pseudoalkaloid Oligoglycoside from Brazilian Natural Medicine, "Fruta do Lobo" (fruit of Solanum lycocarpum). Phytochemistry, v.69, n.7, p.1565-1572, 2008.

NATIONAL COMMITTEE FOR CLINICAL LABORATORY STANDARDS (NCCLS). Performance standards for antimicrobial disk susceptibility tests. Approved standards M7A5. Wayne, PA, 2008.

PASSOS, Fabio Barbosa. Avaliação de Solanumlycocarpum A. St. Hill. (Solanaceae) e de poleiros artificiais como facilitadores na restauração de área perturbada de Cerrado sentido restrito. Dissertação de Mestrado. Universidade de Brasília, Brasília, Brasil. p. 87, 2009. Disponível em: <http://repositorio.unb.br/handle/10482/4456>. Acesso em 01 de jun. 2017.

PEYRET, Michel et al. Mathematical study of the sensitivity curves of Escherichia coli exposed to polymyxins. Pathologie-biologie, v. 38, n. 5, p. 441-445, 1990. Disponível em: <http://europepmc.org/abstract/med/2164182 . Acesso em: 01 de jun. 2017.

PINTO, Lilian Vilalba et al. Mechanism and control of Solanum lycocarpum seed germination. Annals of Botany, v. 100, n. 6, p. 1175-1187, 2007.

PUNJABI, Sangeeta et al. Solasodineglycoalkaloids: a novel topical therapy for basal cell carcinoma. A double-blind, randomized, placebo-controlled, parallel group, multicenter study. InternationalJournalofDermatology, v. 47, n. 1, p. 78-82, 2008.

RIBEIRO, José Felipe; WALTER, Bruno Machado Teles. As principais fitofisionomias do Bioma Cerrado. In Cerrado: ecologia e flora (S.M. Sano, S.P. Almeida \& J.F. Ribeiro, eds.). EmbrapaCerrados, Planaltina. p. 151 -212. 2008.

SCHWARTZ, Aline et al. Phytochemical study of Solanum lycocarpum (St. Hill) unripe fruit and its effects on rat gestation. PhytotherapyResearch, v. 21, n. 11, p. 1025-1028, 2007.

SILVA, Jackeline et al. Atividade inibitória das folhas e caule de Kalanchoe brasiliensis Cambess frente a microrganismos com diferentes perfis de resistência a antibióticos. Revista Brasileira de Farmacolognosia, v. 19, n. 3, p. 790-794, 2009.

SIMÕES, Cláudia Maria Oliveira et al. Farmacognosia: Da planta ao medicamento. 6. ed. Porto Alegre/Florianópolis: Universidade Federal do Rio Grande do Sul, p. 1104, 2010.

VAZ, Nelissa Pacheco. Constituintes químicos de SolanumcaavuranaVell.: Isolamento, mapeamento fitoquímico por IES-EM/EM e sua aplicação no tratamento da hanseníase. Tese (Doutorado). Universidade Federal do Paraná, 176 p. 2010. 